\title{
IMAGENS DAS COLÔNIAS DA EMPRESA DE COLONIZAÇÃO MEYER NO RIO GRANDE DO SUL, 1906
}

Rosane Marcia Neumann

Pontifícia Universidade Católica do Rio Grande do Sul

Seduzir, esse é um dos propósitos da propaganda. Herrmann Meyer ${ }^{1}$, por meio de prospectos, panfletos, anúncios em jornais, apresentava e oferecia o seu produto - um lote colonial em uma colônia no noroeste do Rio Grande do Sul -, despertando o interesse e a imaginação de seu consumidor. A fotografia, com o intuito de propaganda, também foi empregada amplamente por essa companhia colonizadora particular, como prova irrefutável de que aquele lugar era real, fornecendo visualmente os mesmos elementos informativos. As fotografias da colonização preenchiam as fantasias dos expectadores com representações visuais concretas. Postais, vistas urbanas vendiam uma imagem positiva e recorrente da colônia, tanto interna como externamente. Esse recurso contribuía para a constituição de uma imagem "oficial" da colônia. Porém, ao mesmo tempo em que revela a fotografia também oculta. Assim, por intermédio das fotografias, é possível perceber como a Empresa de Colonização Dr. Herrmann Meyer imaginava as colônias Neu-Württemberg - atual município de Panambi, fundada em 1898 no interior do então município de Cruz Alta - e Xingu - atual município de Novo Xingu, fundada em 1897, pertencente então ao município de Palmeira das Missões - e como as apresentava/representava em imagens, retratando/comprovando seu progresso e sustentabilidade.

Cada fotografia é singular, pois apresenta um instante único. O instante fotográfico demarca o propósito da lembrança em oposição ao propósito do

\footnotetext{
${ }^{1}$ Herrmann Meyer nasceu em 11 de janeiro de 1871, em Hilsburghausen, Alemanha. Sua família era proprietária do Instituto Bibliográfico de Leipzig, do qual posteriormente tornou-se sócio-proprietário. Realizou estudos de etnologia nas universidades de Leipzig, Berlim, Estrasburgo e Jena. Seu objeto de estudo eram os indígenas do Brasil Central, o que motivou sua primeira e segunda expedição ao Xingu, no Mato Grosso, respectivamente em 1896 e 1898-99. No transcorrer desses contatos, e após uma viagem pela zona de colonização alemã e italiana do Rio Grande do Sul, em 1898, interessou-se em investir em um projeto de colonização alemã no sul do país, realizando as primeiras compras de terras no noroeste do estado em 1897, adquirindo várias glebas posteriormente ainda. Faleceu em Leipzig em 17 de março de 1932.
} 
esquecimento, numa imbricação profunda entre presença e ausência. A fotografia seria então uma idéia de passado que se quer construir. Fotografar consiste em estabelecer uma distinção entre aquele instante e os demais, e ao mesmo tempo torná-lo passível de ser conhecido.

No final do século XIX, o uso da fotografia para fins de registro e propaganda estava em ascensão, com a modernização dos processos fotográficos (Cf. FREUND, 2002; KOSSOY, 2001,2002; BORGES, 2003). Em 1896, Herrmann Meyer já possuía um aparelho fotográfico portátil, o qual usava nos seus trabalhos de campo, como as viagens ao Brasil. Registrar em imagens para mostrar aos seus compatriotas o que era o Rio Grande do Sul, foi seu objetivo em 1898-99, quando viajou pela zona colonial antiga. Como integrante de uma editora, conhecia também o poder de sedução exercido por uma fotografia, especialmente quando utilizada para fins de publicidade. Ciente dessas possibilidades, registrou em imagens fotográficas o crescimento de seu complexo colonial, sob diferentes ângulos, de modo contínuo, contratando para isso os serviços de um fotógrafo. Dispor de um acervo fotográfico atualizado das colônias servia também para exibir no seu círculo de relações e aos emigrantes interessados em migrar para essa região. Ainda, foi a forma encontrada por Herrmann Meyer para visualizar as suas colônias à distância, uma vez que não viajou mais para o Brasil.

Em novembro de 1899, seu procurador e sócio Carlos Dhein informou, em carta a Herrmann Meyer, que nos próximos dias pretendia enviar uma correspondência com uma série de fotografias da colônia Neu-Württemberg e Xingu, de sua autoria, pois arranjara um aparelho fotográfico, com o qual conseguia tirar fotografias bonitas, já havendo tirado algumas do acampamento e da agricultura. Caso Meyer se interessasse pelo material, produziria mais imagens. Porém, solicitava que Ihe enviasse algumas chapas $13 \times 18$, porque no Brasil estas eram muito caras. ${ }^{2}$ A inviabilidade econômica levou-o a vender o aparelho já no final daquele mesmo ano, quando então sugeriu a Meyer que este Ihe enviasse um aparelho fotográfico usado, dado que possuía vários. ${ }^{3}$

Em 1906, Herrmann Meyer editou pelo Instituto Bibliográfico de Leipzig um prospecto fotográfico sobre o seu projeto de colonização, justamente no

\footnotetext{
${ }^{2}$ Carlos Dhein a Herrmann Meyer, Cruz Alta, 22 de novembro de 1899. Caixa 63, Museu e Arquivo Histórico Panambi - MAHP.

${ }^{3}$ Carlos Dhein a Herrmann Meyer, Cruz Alta, $1^{\circ}$ de janeiro de 1900. Caixa 63, MAHP.
} 
momento mais frágil da Empresa de Colonização. Ansichten aus Dr. Herrmann Meyers Ackerbaukolonien Neu-Württemberg und Xingu in Rio Grande do Sul (Südbrasilien) - Vista da colônia agrícola Neu-Württemberg e Xingu no Rio Grande do Sul (sul do Brasil) - foi apresentado com uma pequena nota no verso da capa, como "um prospecto pormenorizado sobre as colônias, gratuito; para receber: Escritório do Empreendedor, Leipzig, Bismarckstrasse, 1". A imagem fala por si própria, daí dispensar maiores explicações, restringindo-se a uma legenda curta para identificar o local de obtenção da imagem e o tema ali representado.

O acabamento do prospecto era simples, com capa neutra, pouco chamativa, e as páginas internas em papel liso, num total de 27 páginas não numeradas. Constam 47 fotografias, em preto e branco, dentre as quais, 7 de página inteira. Relativo aos temas, é possível classificá-los, grosso modo, da seguinte forma: natureza/recursos hídricos 4; agricultura/criação 9; construções/casas dos colonos 16; igreja/escola/sociedades 6; vistas 3; oficinas/casas comerciais 3; derrubada da mata/instalação provisória 6 . Predominam, em larga escala, as fotografias de construções de casas dos imigrantes, no modelo retrato, sendo estas em sua totalidade construções em madeira, geralmente com seus moradores pousando em frente às mesmas. Quanto ao local, 45 fotografias são da colônia Neu-Württemberg, e apenas duas da colônia Xingu.

No material não consta quem foi o fotógrafo ou fotógrafos, nem se ele era do Rio Grande do Sul ou enviado da Alemanha. O acabamento das fotografias e os seus ângulos denotam trabalho de um profissional. Cabe lembrar que o fotógrafo é o responsável imediato pela seleção das melhores vistas, colocando-as em circulação, em consonância com os interesses seus ou os dos consumidores/financiadores - no caso, tratava-se de uma publicação financiada pela Empresa de Colonização Dr. Herrmann Meyer, com fins de propaganda em prol da emigração da Alemanha para as colônias Neu-Württemberg e Xingu, no Rio Grande do Sul.

As fotografias, no seu conjunto, exibiam ao mesmo tempo o rústico da vida nas colônias e o belo, bem como as possibilidades de produção. Ainda, asseguravam que em menos de uma década, os imigrantes e migrantes alemães haviam domado a selva, transformando-a em grandes lavouras de milho e tabaco, além de outras culturas, paralelo a uma criação de animais diversificada. 
Nesse contexto, como ressalta Gilmar Arruda (2005), a imagem fotográfica estava a serviço da venda de um produto, de uma mercadoria, naquele momento, a terra. Por isso, as primeiras fotografias eram produzidas com o objetivo de mostrar a vitalidade da terra, expondo a exuberância da natureza e, ao mesmo tempo, a viabilidade do projeto imobiliário, através de elementos urbanos já presentes no meio da floresta. Simbolicamente, comprovava que o homem podia vencer a mata fechada, dando lugar à civilização. O suporte mais preciso/próximo do real para registrar essas transformações era a fotografia.

Esse conjunto fotográfico consistiu em um primeiro balanço para o público da colonização, após nove anos de investimentos na colônia Xingu e oito na colônia Neu-Württemberg. Mostrava esse espaço como dinâmico, em constante transformação, criado e recriado a cada dia, próspero e moderno. Um convite explícito para a emigração.

O ordenamento das fotografias no prospecto não seguia uma seqüência temática rígida. As primeiras quatro fotografias apresentavam temas mais gerais, como recursos hídricos, estrada principal da colônia, serraria e moinho.

A primeira fotografia do prospecto, de página inteira, na horizontal, destacava a riqueza dos rios que banhavam a colônia Neu-Württemberg (Foto 1 ). No rio Palmeira, em foco no primeiro plano, havia uma série de pequenas quedas d'água, que poderiam ser exploradas como força motriz, dado o seu volume de água. Em meio à mata, que ocupava ambas as margens do rio, aparecem as benfeitorias da propriedade de uma família de colonos. Como o rio abastecia as famílias, construir nas proximidades facilitaria o transporte da água. Na curva do rio, onde ele parece ser mais estreito, é possível identificar uma ponte de cordas ou pinguela para permitir a comunicação com a outra margem - que então pertencia ao município de Palmeira. 


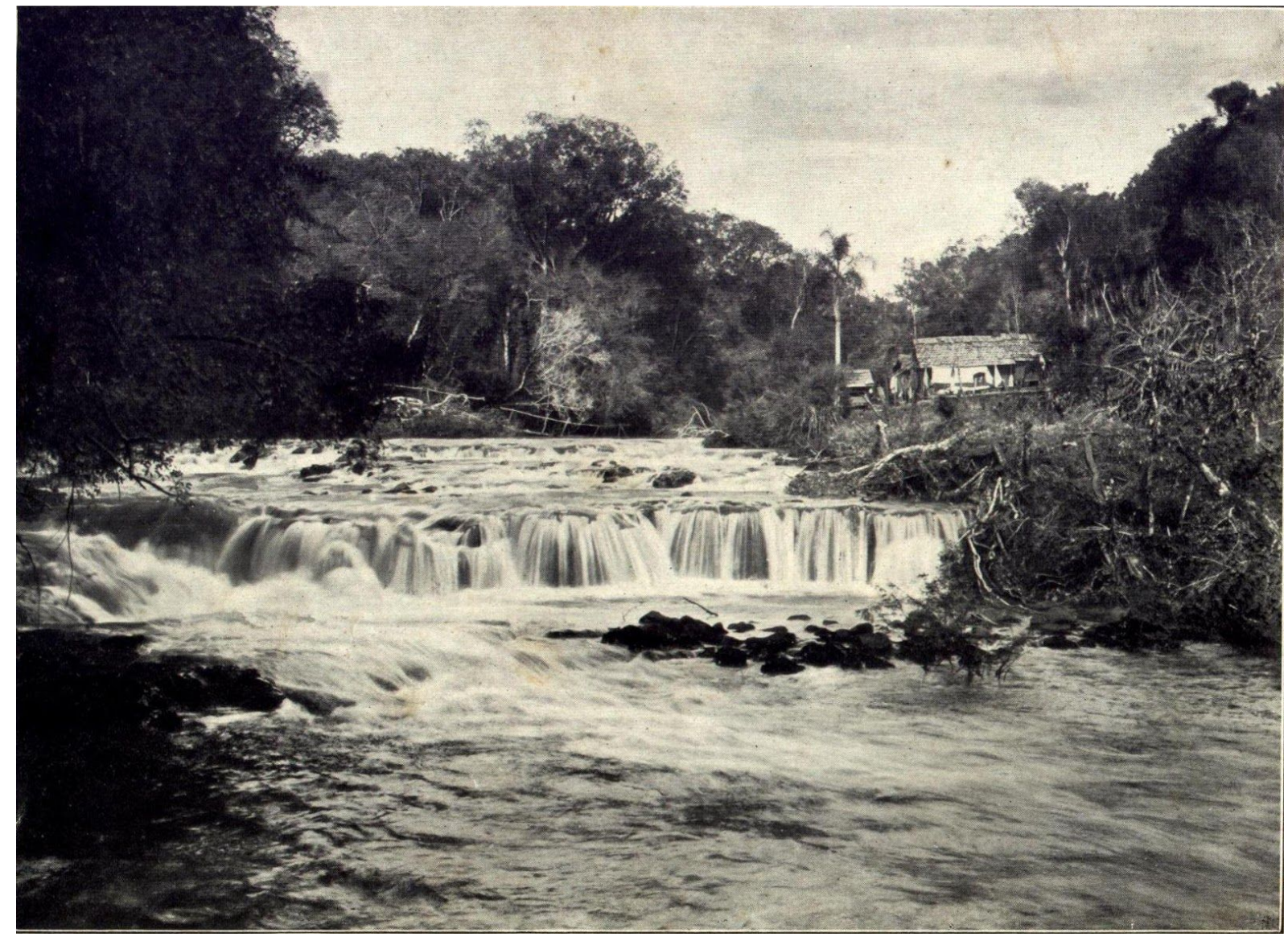

Foto 1 - Queda d'água no rio Palmeira (Neu-Württemberg) ${ }^{4}$ Fonte: MEYER, 1906b: fl. 1

Ao longo do prospecto, percebe-se uma clara diferença entre as construções dos colonos e as construções de propriedade da Empresa de Colonização Dr. Herrmann Meyer, ainda que todas fossem em madeira. As casas dos colonos eram simples, pequenas, ao rés-do-chão, com janelas sem vidro, sem pintura, não diferindo muito dos galpões e estábulos. Por sua vez, as benfeitorias da Empresa de Colonização eram amplas, com traços arquitetônicos bem definidos, o que ficou evidente pelos retratos da casa pastoral, casa do imigrante, moradia do diretor da colônia e dependências da administração da Empresa, colocados numa seqüência no prospecto, todas elas instaladas na colônia Neu-Württemberg.

Em 1901, a Empresa de Colonização, com o auxílio dos colonos já instalados, ergueu a "Casa dos Imigrantes" ou "Barracão dos Imigrantes", como

\footnotetext{
${ }^{4}$ São mantidas as legendas originais das imagens, traduzidas para o português.
} 
ficou conhecido. Concluído e inaugurado no segundo semestre daquele ano, com celebração de culto por um pastor da missão batista, passou a abrigar, a partir de então, os imigrantes, a escola e a celebração de cultos. Tratava-se de uma construção rústica em madeira, sem pintura, utilizando telhas de madeira, com portas e janelas estreitas (Foto 2). Na ocasião da tomada fotográfica, obtida na diagonal do prédio, um grupo de imigrantes e migrantes pousou defronte às portas e janelas, destacando-se dois personagens em primeiro plano. Dispor de um local para abrigar os recém-chegados contava como mais um ponto positivo para a Empresa de Colonização e as suas colônias.

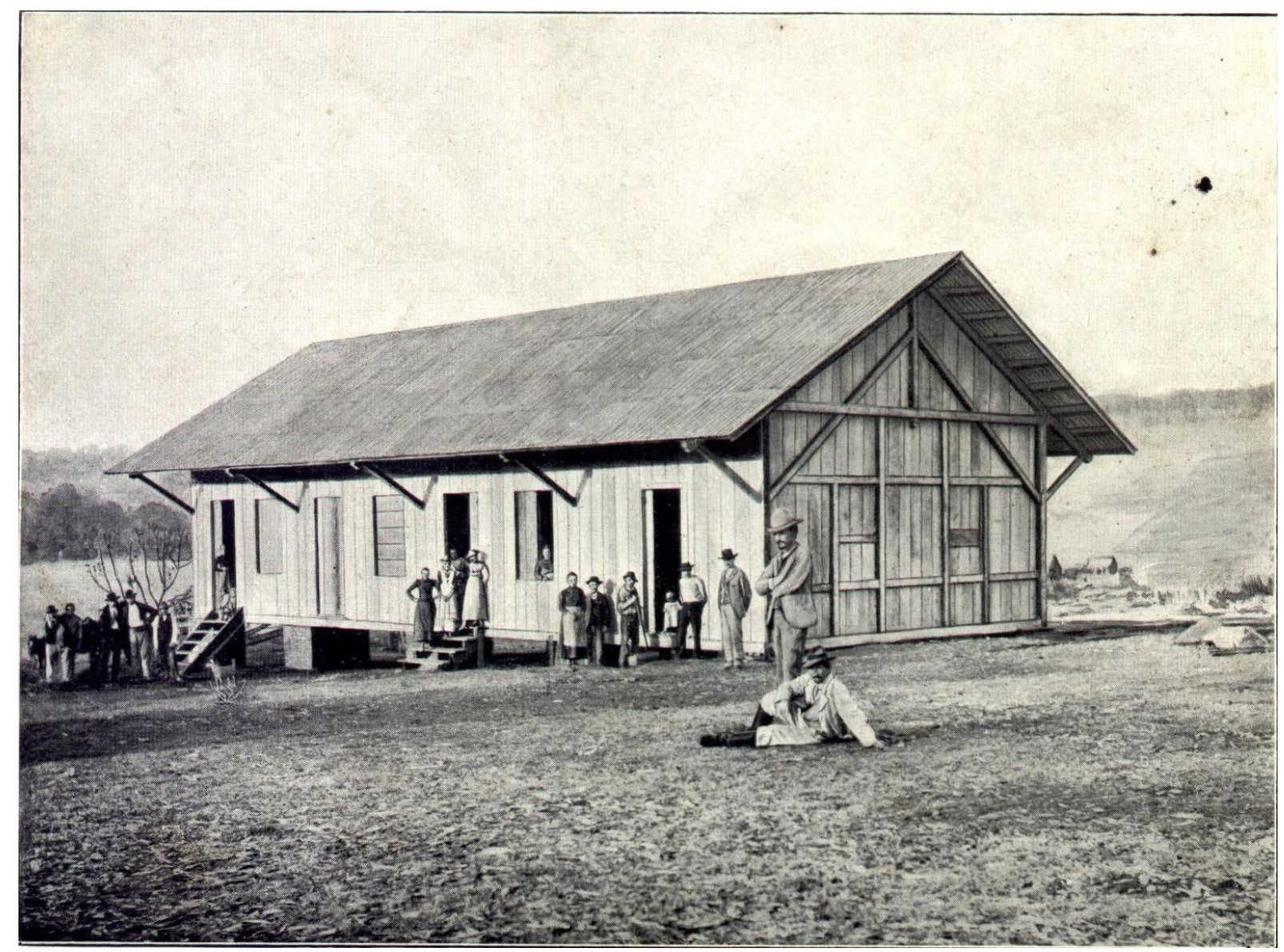

Foto 2 - Casa do Imigrante em Neu-Württemberg Fonte: MEYER, 1906b: fl 4

Em dezembro de 1902, foi concluída a casa pastoral, já com um acabamento arquitetônico diferenciado, com seu telhado extremamente inclinado, com detalhes em madeira trabalhada, janelas com vidraças e alguns 
detalhes com madeira cruzada tipo enxaimel. Contudo, a construção mais imponente, com dois pavimentos, do lado oposto do morro da escola e da casa pastoral, um pouco afastada da área central, foi a "residência do diretor da colônia" (Foto 3). A construção, obra do marceneiro e construtor Karl Knorr, um imigrante alemão residente na colônia, foi concluída em meados de 1906, consumindo uma grande soma de capital. Uma arquitetura bem definida, com alicerces de pedra, tábuas trabalhadas, acabamento com detalhes, grandes janelas, telhado de zinco, são alguns dos diferenciais. O retrato da edificação, obtido de um nível mais baixo, denotava a posição da qual a sede urbana via a residência do diretor ou qualquer pessoa que para lá se dirigisse, - ao mesmo tempo, conferia uma visão privilegiada ao diretor sobre a colônia.

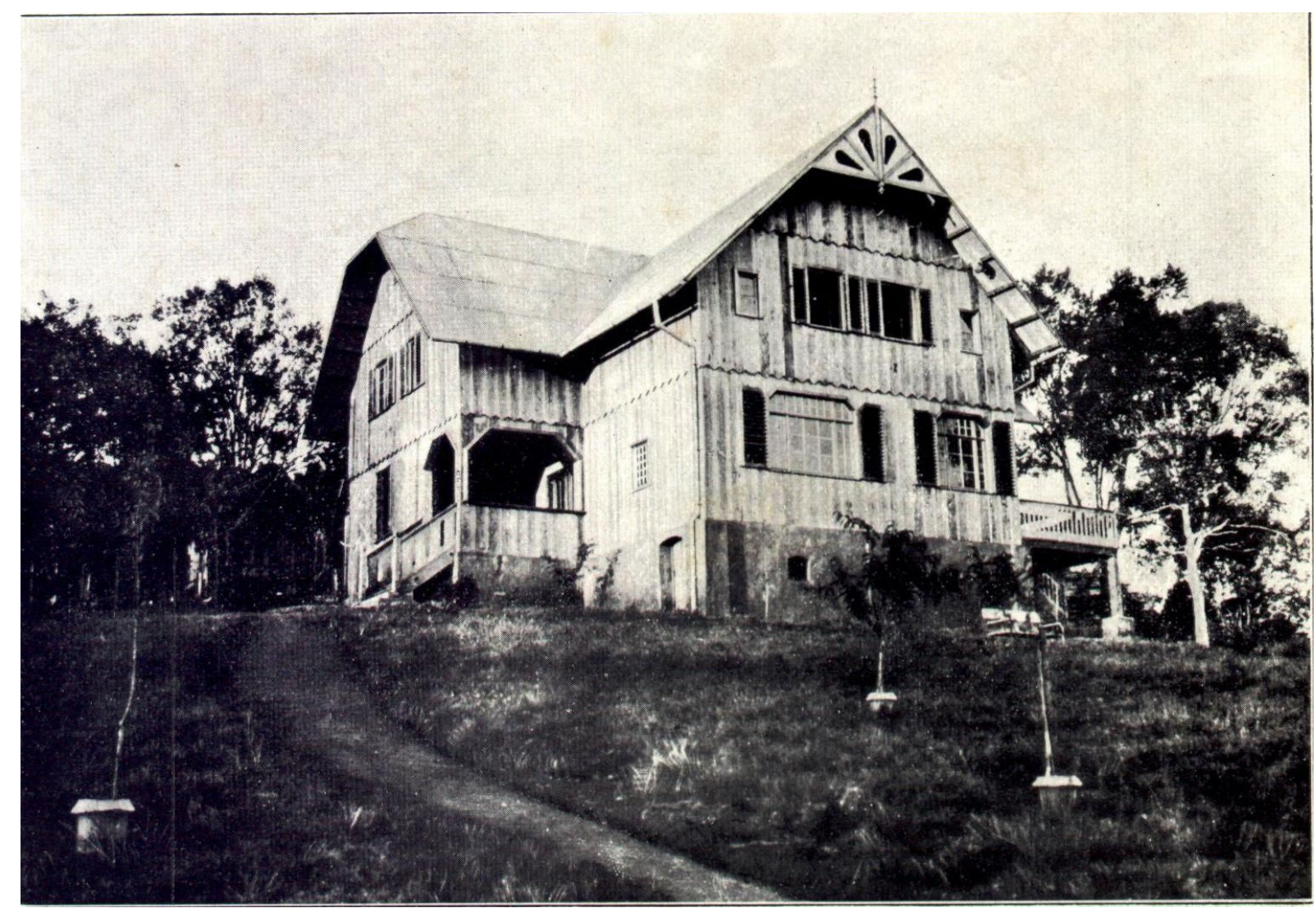

Foto 3 - Residência do diretor da colônia em Neu-Württemberg Fonte: MEYER, 1906b: fl.5

Segundo Meyer, em suas colônias o atendimento escolar e religioso não era negligenciado. Como sinal disso, o prospecto trazia duas fotografias de ofícios religiosos - um grupo de fiéis após o culto e um batizado ao ar livre - e 
duas de atividades escolares - uma de um grupo de alunos na aula de ginástica, e a outra de um grupo de crianças com seus professores, casal Faulhaber, mais alguns pais na saída da escola (Foto 4). Note-se que a fotografia foi obtida de surpresa, com as crianças se movimentando de forma espontânea, distribuídas de modo desordenado, ocupando toda a linha central da imagem. Pelos olhares das três senhoras montadas em seus cavalos à esquerda, e de algumas crianças, algo aconteceu que desviou a sua atenção das lentes do fotógrafo: provavelmente os dois meninos em pé na sela de seu cavalo, à direita. $\mathrm{Na}$ extrema direita, delimitando a imagem, o prédio da escola de Neu-Württemberg e, à sua frente, os professores e mais algumas pessoas. Ao fundo, os resquícios da mata nativa. Crianças bem vestidas, outras nem tanto, meninas com seus chapéus, meninos com seus terninhos e chapéus ou bonés. No grupo dos meninos, vários de ascendência luso-brasileira, bem como os senhores ao fundo. Como era a única escola até então na colônia, as crianças se deslocavam por longas distâncias, utilizando para isso o meio de transporte disponível: o cavalo, representativo na imagem.

O Clube de Lanceiros, a Sociedade de Cantores, juntamente com as festas preenchiam os momentos culturais e de lazer da população colonial, como também atestavam as fotografias. 


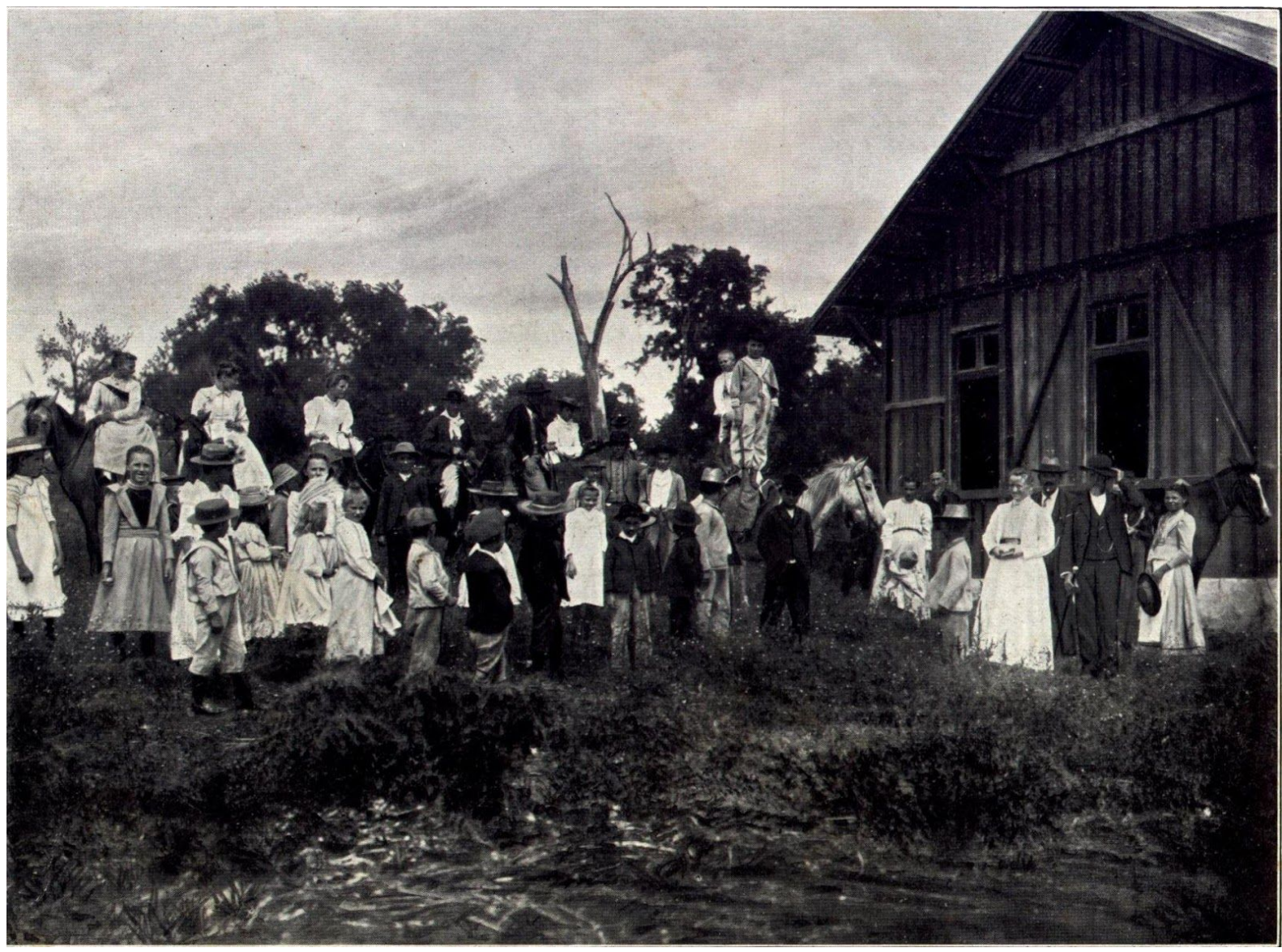

Foto 4 - Jovens escolares em Neu-Württemberg Fonte: MEYER, 1906b: fl.7

A sede urbana ou Stadtplatz Elsenau foi a área mais fotografada de Neu-Württemberg, sob todos os ângulos, produzindo várias vistas parciais e panorâmicas. As lentes dos fotógrafos acompanharam o seu gradual crescimento até assumir os contornos de uma cidade. Almerinda Lopes (2003: 261) lembra que o termo "vista" "indica certa singularidade, do ponto focal, como um momento particular de uma representação complexa do mundo que é um tipo de atlas topográfico total". Essencialmente, é um recorte de um todo.

Um reduzido número de casas de madeira, pequenas e rústicas, cobertas com telhas de madeira e enfileiradas, ao seu redor cercados para a criação de animais compunham o cenário da sede urbana Elsenau em 1905/1906 (Foto 5). O que a diferenciava da área rural eram as suas quadras com terrenos e ruas demarcadas. Nesse espaço, não havia mais vestígios da mata, restando somente uma vegetação rasteira e uma considerável quantidade de troncos a serem 
serrados. Para além das casas, a mata se confundia com o terreno ondulado. Essa infra-estrutura da colônia Neu-Württemberg era então uma das razões para o alto custo dos lotes coloniais e terrenos, e a fotografia uma prova irrefutável, frente à concorrência, de sua realidade.

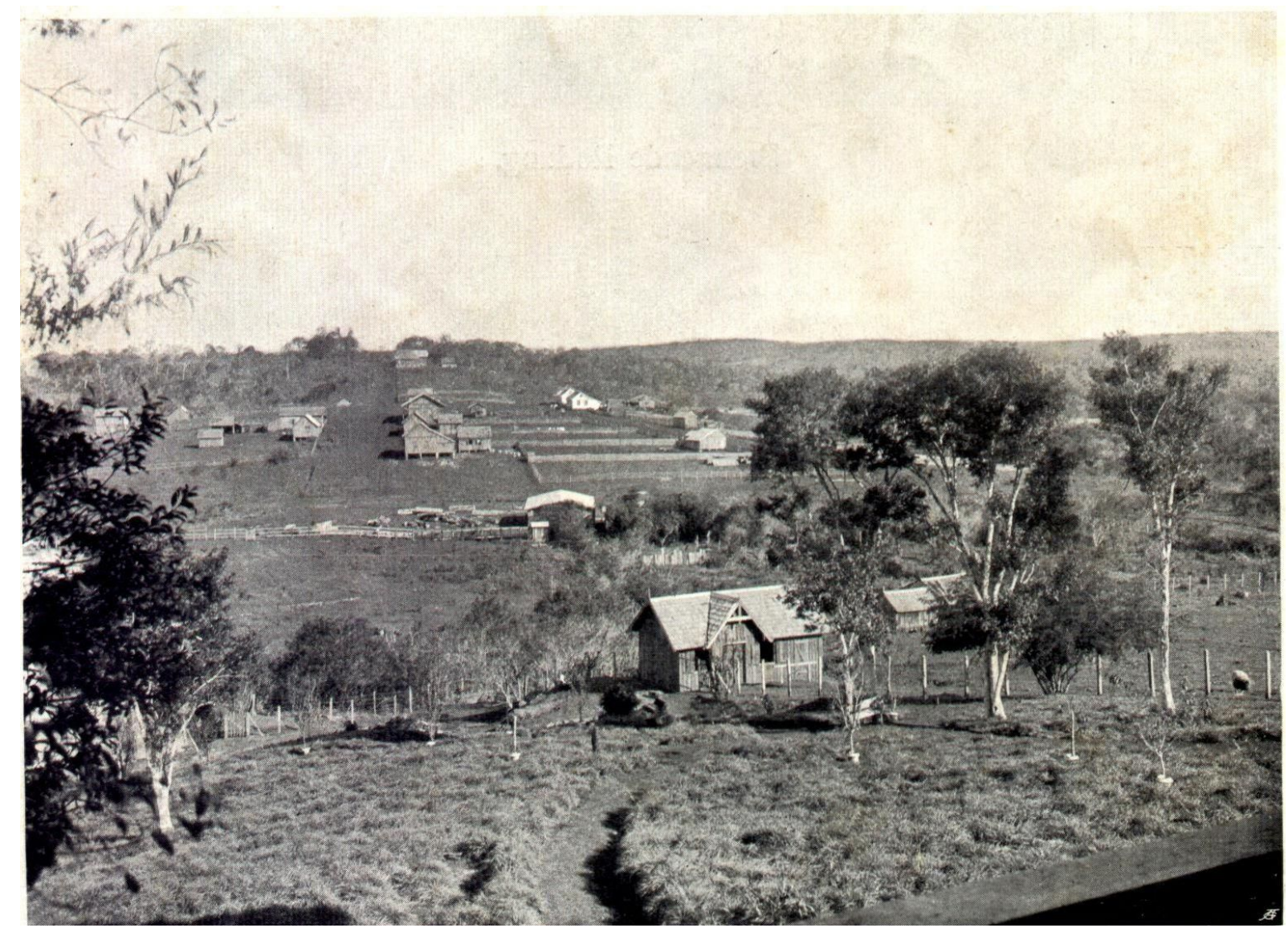

Foto 5 - Parte da Stadtplatz Elsenau

Fonte: MEYER, 1906b: fl. 20

O "sistema de roças", conhecido na literatura alemã como Raubbau ou Raubsystem, vigente no Rio Grande do Sul, foi uma novidade para o camponês alemão. A derrubada da mata nativa requeria conhecimento e prática. No tempo certo, quando os restos da vegetação estavam secos, realizava-se a queimada, como registrada pelo fotógrafo (Foto 6). Em meio aos grossos galhos secos das árvores, à direita, dois meninos, observando o início da queimada, cuja fumaça tomava conta do espaço. Ao fundo, a mata fechada, estabelecendo o limite para o fogo e para a lavoura. 


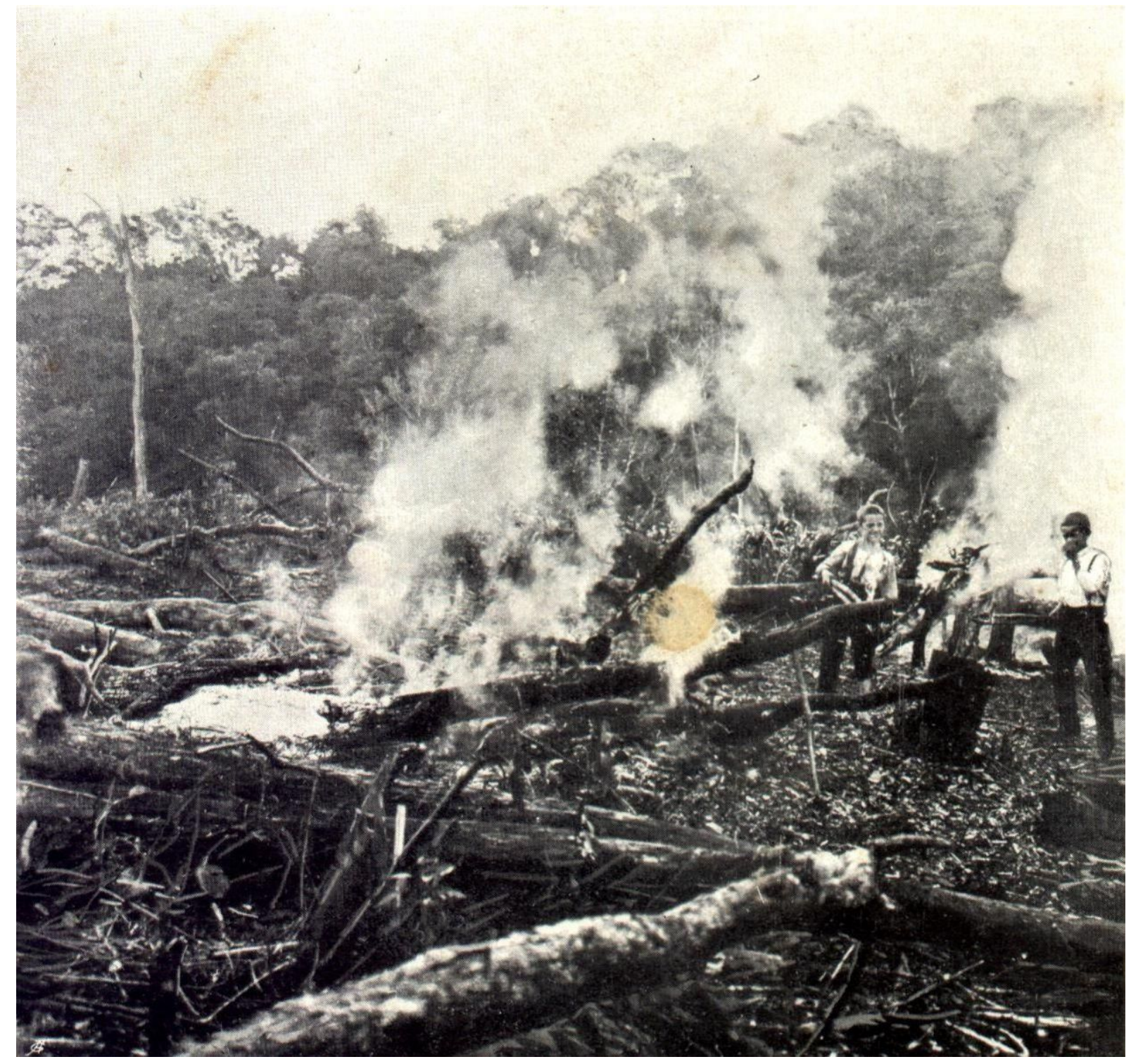

Foto 6 - Queimada da mata derrubada Fonte: MEYER, 1906b: fl. 19

Ao adquirir o seu lote colonial, seguindo as orientações de Meyer e levado pelas próprias limitações do meio, o colono instalava-se provisoriamente, construindo a sua cabana, improvisando a sua existência, até derrubar uma área de mato e proceder ao plantio. À primeira vista, a imagem da "primeira cozinha dos colonos" é desoladora, dando bem conta do modo de vida simples ao qual Meyer se referia (Foto 7). Algumas estacas frágeis, com uma cobertura de palha, abrigavam os pouquíssimos utensílios da cozinha. Caixotes serviam como mesa e armário, os troncos das árvores ali estavam para serem cortados e lascados para 
telhas, ou para servirem como bancos. Atrás da cozinha improvisada, um tanto obscurecida, uma outra pequena construção, que provavelmente abrigava a família. Apesar da rusticidade, o imigrante ou migrante alemão vivendo nessas condições era o proprietário de suas terras, de sua produção, e de tudo o mais que ali houvesse. Um lote colonial de 25 hectares era uma área considerável para os parâmetros de propriedade de pequenos camponeses na Alemanha na época. Outro indício de que valia a pena migrar e se submeter a essas dificuldades era a quantidade de animais para o trabalho que a família já possuía: um cavalo e três mulas, enquanto na Europa o cavalo era de posse restrita da alta elite. E mais: se na Europa a obtenção de lenha era problemática após o cercamento dos campos públicos, na "nova pátria" havia uma mata inteira para ser explorada.

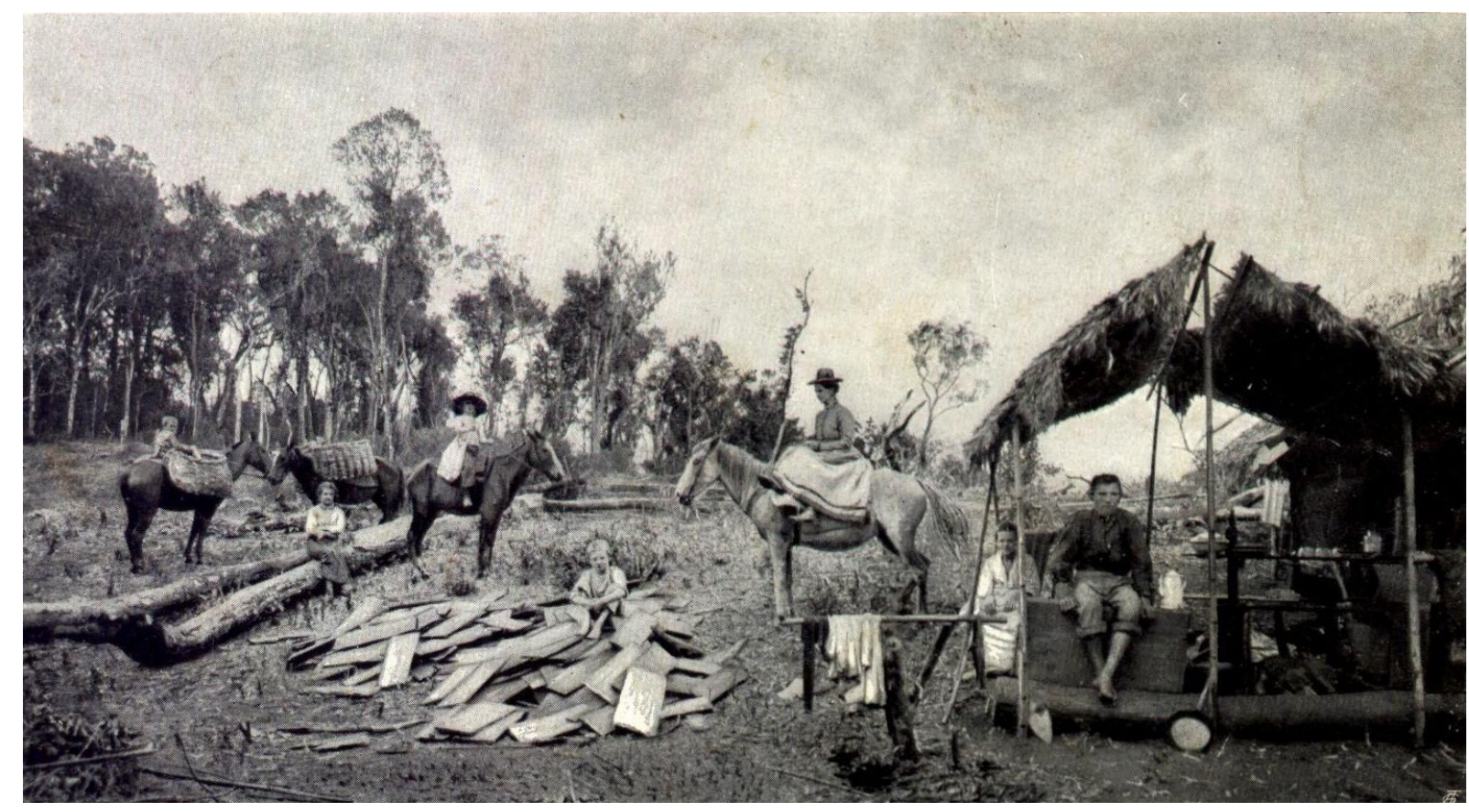

Foto 7 - A primeira cozinha dos colonos em Neu-Württemberg Fonte: Fonte: MEYER, 1906b: fl. 19

Nas três fotografias sobre a instalação provisória do colono na mata, apenas em uma aparece um homem pousando com sua família. Nas demais, como na anterior, apenas as mulheres com seus filhos menores, nas 
proximidades da cabana - os meninos, descalços e com suas roupas cotidianas em contraste com a senhora de chapéu e vestido em seu animal de montaria.

Entretanto, nem todos os imigrantes e migrantes que se dirigiram a Neu-Württemberg, motivados pela propaganda, se adaptaram ao modo de vida estampado na fotografia. Os que detinham certo capital abandonaram o lote logo em seguida e regressaram para a Alemanha. Os demais não tiveram tal sorte ou possibilidade. O pastor Hermann Faulhaber, em 1903, referindo-se a esse movimento, afirmava: "trabalho e não 'pombas assadas voando'. Pequeno agricultor e nenhuma salvação. É muito difícil e triste ser colono" (FAULHABERSTIFTUNG, 1933: 15).

Em menos de uma década, os colonos conseguiram acumular capital suficiente para construir uma casa apropriada para abrigar a sua família, bem como galpões, estábulos, currais. Novas áreas de matas haviam sido incorporadas às roças, aumentando a produção agrícola, paralela à criação de gado e porcos, além da manutenção de cavalos e mulas para o trabalho. 0 prospecto tentava mostrar esse contraste: ao mesmo tempo em que apresentava as três fotografias da fase de instalação dos colonos, com as dificuldades concernentes, na seqüência, trazia uma série de fotografias de "casas de colonos", exibindo construções sólidas e bem acabadas, geralmente com a família pousando em frente às mesmas, em meio a vastas plantações. Em outros termos, preocupar-se primeiro em cultivar as suas roças e prover o seu sustento, revertia em acúmulo de capital suficiente para prover as demais necessidades, como as construções e a ampliação da área de cultivo, atendendo às orientações de Herrmann Meyer. Em 1906, a colônia Neu-Württemberg já contava com extensas plantações de milho, tabaco e mandioca. Predominava o plantio de milho, usado no trato dos animais e para o consumo da família sob a forma de farinha, ocupando áreas extensas, recuando cada vez mais a mata (Foto 8). 


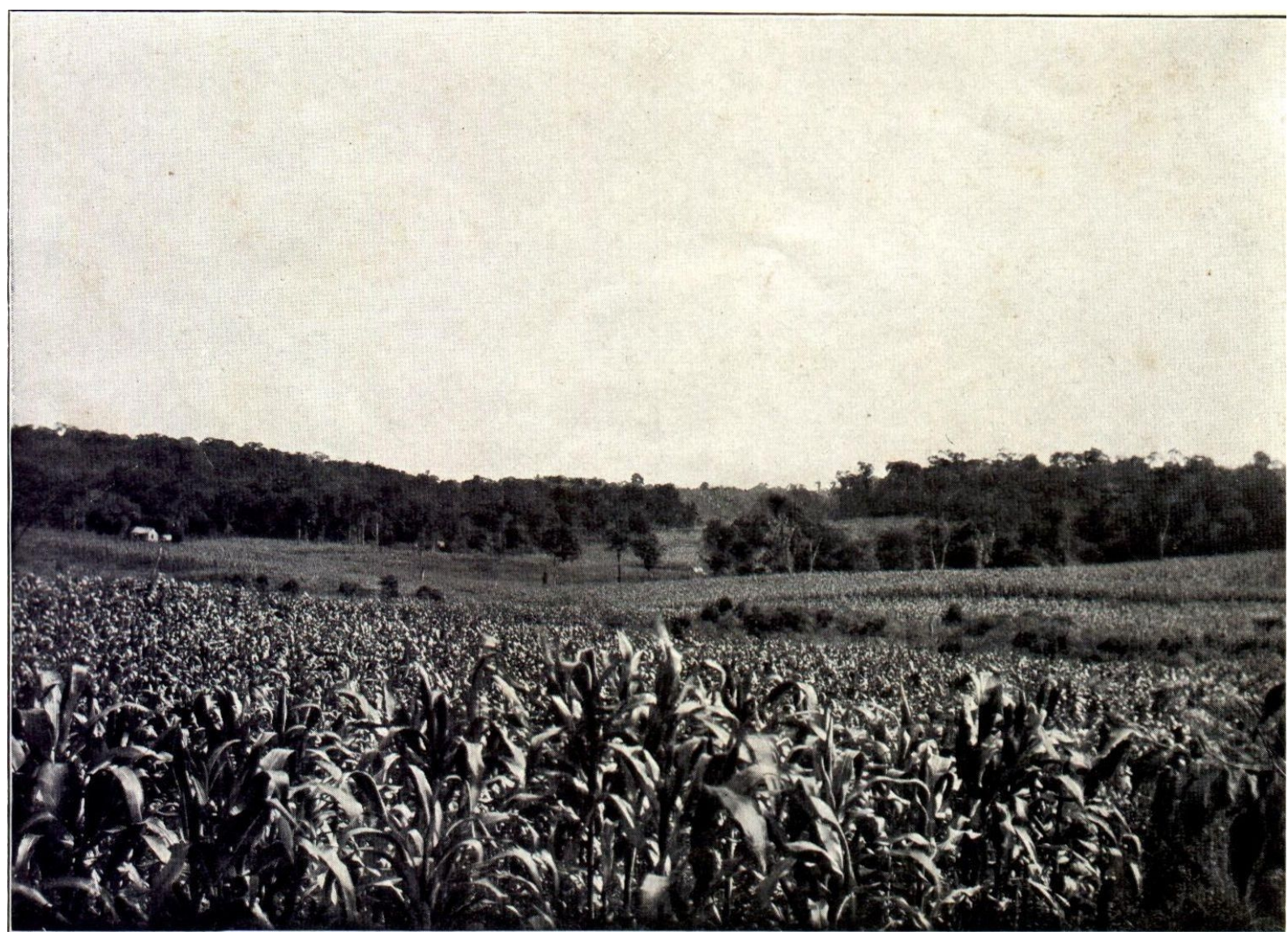

Foto 8 - Plantação de milho de um colono em Neu-Württemberg Fonte: MEYER, 1906b: fl. 25

Uma vista panorâmica de um lote colonial deixa evidente que se tratava de um espaço dinâmico, em constante transformação (Foto 9). Ao mesmo tempo, a coexistência de diferentes estágios do "sistema de roças": a imagem praticamente divide-se por uma linha curva ao meio, à sua direita, restos desordenados de vegetação derrubada, secando ao sol, cercando as duas benfeitorias, no vale uma vegetação rasteira ou capoeiras; à esquerda, na parte mais elevada do terreno, as roças de milho e tabaco, intercaladas por algumas árvores isoladas. Como limite para ambos, a mata nativa, como possibilidade de expansão. 


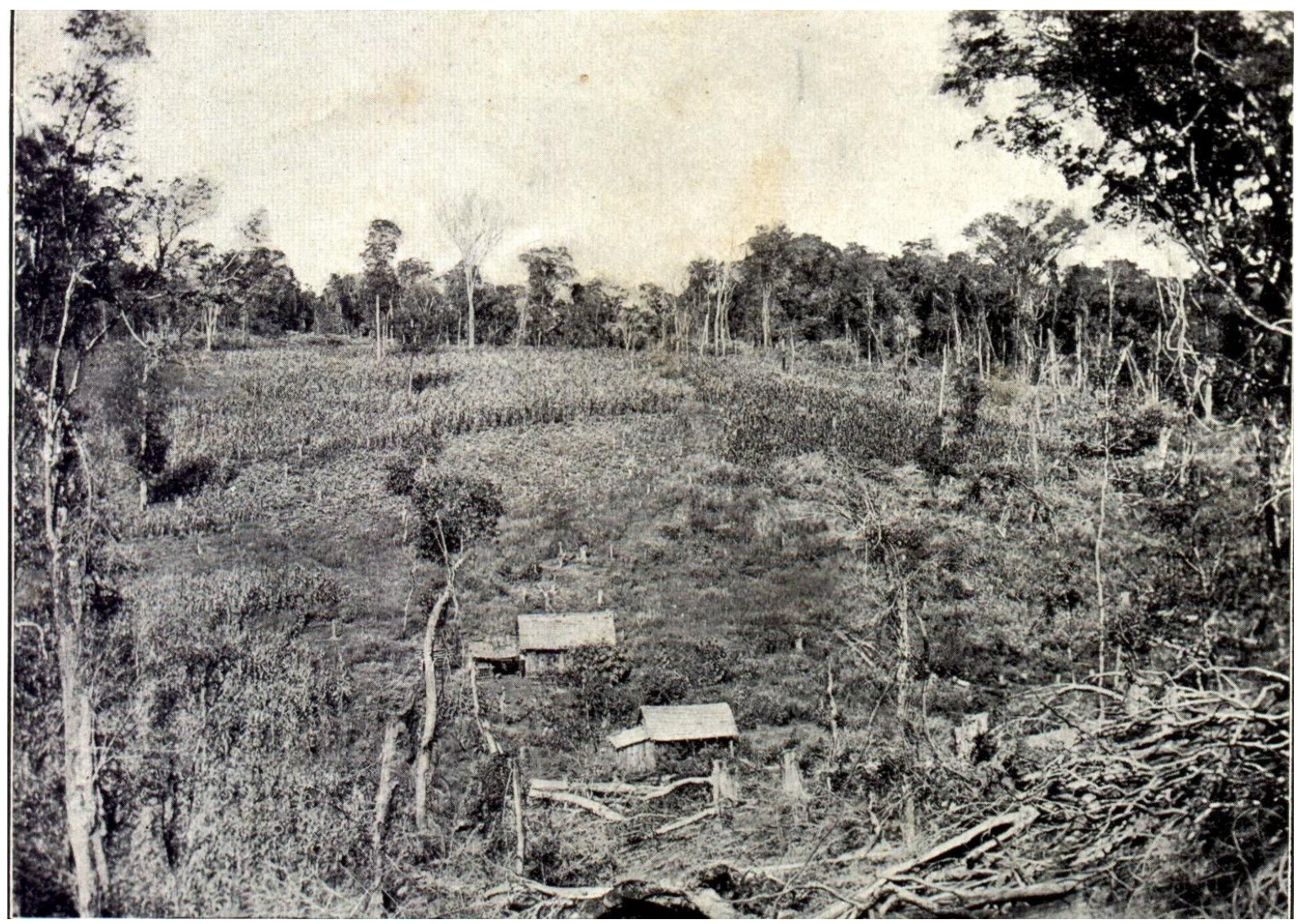

Foto 9 - Vista geral de uma colônia com lavoura de milho e tabaco em Neu-Württemberg

Fonte: MEYER, 1906b: fl. 26

No prospecto fotográfico, Herrmann Meyer reafirmava visualmente a sua concepção de colonização, quem estava apto a integrar seu projeto e as condições de vida nas colônias. Porém, pela primeira vez, apresentou resultados reais e visíveis de seu projeto de colonização no Rio Grande do Sul, assegurando a condição de bem-estar e prosperidade dos imigrantes e migrantes ali estabelecidos. Aos camponeses destinavam-se os lotes rurais, e para os imigrantes urbanos e de ofício, a sede urbana. Contudo, importava que tornar-se-iam, independente da escolha, proprietários. Foi também, mais uma vez, a consagração da colônia Neu-Württemberg como a "colônia modelo" da Empresa de Colonização, com a infra-estrutura existente que elevava os preços dos lotes de terras, os quais eram bem inferiores na colônia Xingu. 
Se o fotógrafo atua como um filtro cultural, o seu leitor também olha para a fotografia a partir de sua cultura, selecionando o que deseja ver ou não. Kossoy (2002) ressalta que a imagem fotográfica entendida como documento/representação, contém em si realidades e ficções, o que a torna ambígua. Apesar dessas particularidades, a imagem fotográfica fornece provas, indícios, e funciona sempre como documento iconográfico acerca de uma dada realidade, um testemunho que contém evidências sobre algo que em algum momento existiu.

Referências bibliográficas:

ARRUDA, Gilmar (2005). Monumentos, semióforos e natureza nas fronteiras. In: ARRUDA, Gilmar (Org.) (2005). Natureza, fronteiras e territórios: imagens e narrativas. Londrina: Eduel.

BORGES, Maria Eliza Linhares (2003). História \& Fotografia. Belo Horizonte: Autêntica.

FAULHABERSTIFTUNG (1933). Neu-Württemberg. Eine Siedlung Deutscher in Rio Grande do Sul/ Brasilien. Stuttgart: s.ed.

FREUND, Gisele (2002). La fotografia como documento social. 10 ed. Barcelona: FotoGrafia.

KOSSOY, Boris (2001). Fotografia e História. 2. ed. São Paulo: Ateliê.

KOSSOY, Boris. (2002). Realidades e ficções na trama fotográfica. 3. ed. São Paulo: Ateliê.

LOPES, Almerinda da Silva (2003). Albert Richard Dietze: um artista-fotógrafo alemão no Brasil do século XIX. Vitória: A1.

MEYER, Herrmann (1906a). Ackerbaukolonien. Neu-Wuerttemberg und Xingu in Rio Grande do Sul (Südbrasilien). Leipzig: Bibligraphischen Institut. 
MEYER, Herrmann. (1906b). Ansichten aus Dr. Herrmann Meyers Ackerbaukolonien Neu-Württemberg und Xingu in Rio Grande do Sul (Südbrasilien). Leipzig: Bibliographischen Institut.

Texto recebido em 18/09/2007. 